\title{
QUALIDADE TECNOLÓGICA DO CAFÉ (Coffea arabica L.) PRÉ-PROCESSADO POR "VIA SECA" E "VIA ÚMIDA" AVALIADA POR MÉTODO QUÍMICO
}

\author{
Rildo Araujo Leite ${ }^{1}$, Paulo César Corrêa ${ }^{2}$, Maria Goreti de Almeida Oliveira ${ }^{3}$, \\ Fernando Pinheiro Reis ${ }^{4}$ e Tânia Toledo de Oliveira ${ }^{5}$
}

\begin{abstract}
RESUMO
Este trabalho visou estudar métodos simples, objetivos e mensuráveis, para avaliação da qualidade do café. Avaliou-se o efeito do tempo de armazenamento da qualidade do café "coco", "descascado" e beneficiado e a atividade da enzima polifenoloxidase (PPO) medida em espectrofotômetro, como método objetivo para determinação da qualidade do café, comparando-o com o método sensorial clássico. A avaliação sensorial foi realizada na Cooperativa dos Produtores de Café de Guaxupé MG, onde foram feitos os testes de classificação quanto ao tipo e à cor. Para a avaliação objetiva, foram feitos os testes químicos para determinação da atividade da polifenoloxidase, utilizando-se a metodologia descrita por Fujita et al. (1995). Com base nos resultados obtidos nos testes experimentais, concluiu-se que a qualidade da bebida avaliada pelo "teste de xícara" manteve-se constante durante o armazenamento, exceto no caso do café descascado que, a partir de seis meses, apresentou queda de qualidade. Existe uma correlação positiva entre cor e qualidade da bebida. Durante o período de armazenamento, todos os tipos de café apresentaram variação de cor, tendendo ao branqueamento; no café beneficiado esta tendência foi mais marcante.
\end{abstract}

Palavras-chave: café, bebida, enzima, espectrofotômetro

\section{QUALITY EVALUATION OF NATURAL AND WASHED COFFEE (Coffea arabica L.) BY CHEMICAL METHOD}

\begin{abstract}
This research aimed to study the simple, objective and measurable methods for evaluating the coffee quality. Evaluation was performed for the effects of storage time on quality of the natural, pulped and green coffee as well as the activity of the polyphenoloxydase enzyme (PPO) measured in spectrophotometer as an objective method for determining coffee quality. This method was compared with the classic sensorial method. The sensorial evaluation was performed at the Cooperativa dos Produtores de Café de Guaxupé - MG, where the classifying tests were conducted for type and color. For objective evaluation, the chemical tests were performed to determine the activity of the polyphenoloxydase enzyme using the methodology developed by Fujita et al. (1995). Based on the obtained results it was concluded that the drink quality evaluated by "cupping" maintained constant during the storage time except for pulped coffee, which presented quality decline from six month.
\end{abstract}

\footnotetext{
${ }^{1}$ Eng. Agrícola, Mestre, Departamento de Engenharia Agrícola, UFV., CEP 36571-000, Viçosa, MG.

2 Professor Adjunto, Departamento de Engenharia Agrícola, UFV.,

3 Professora Adjunta, Departamento Bioquímica e Biologia Molecular, UFV

${ }^{4}$ Professor Adjunto, Departamento Informática, UFV

${ }^{5}$ Professora Adjunta, Departamento Bioquímica e Biologia Molecular, UFV
} 
There is a positive correlation between color (PPO) and drink quality. During the storage time all coffee types presented color variation tending to whitening. This tendency was more evident in the green coffee.

Key words: coffee, drink, enzyme, spectrophotometer

\section{INTRODUÇÃO}

Menchú (1967) relata que, naquela época, os procedimentos de avaliação da qualidade do café limitavam-se, apenas, a uma série de apreciações subjetivas de aromaticidade, sabor e aspecto do produto, ignorando as causas dos danos físicos e/ou químicos, devido aos diversos agentes causadores que depreciam este produto. Profissionais treinados, cuja habilidade deve ser adquirida através de anos de experiência, são os responsáveis pela avaliação subjetiva do café, em que a atual classificação da sua qualidade, de acordo com o aspecto, o tipo e a classificação da bebida, por prova de xícara, poderia ser complementada com a adoção de métodos físicos e químicos, que facilitariam a avaliação, tornando-a menos subjetiva.

Vários estudos demonstram existir relação entre alguns componentes químicos do grão beneficiado e a qualidade do café. Devido à importância do café para o país e para o mundo, é necessário o complemento de métodos objetivos (físicoquímicos e/ou químicos) juntamente com as classificações tradicionais já existentes proporcionando, assim, uma avaliação mais segura da qualidade deste produto (Carvalho, 1994).

Segundo Amorim (1978) esta enzima, quando "in vivo", é encontrada ligada às membranas celulares e é ativada somente quando liberada. Quando a membrana celular sofre algum dano, a enzima é liberada e ativada ao mesmo tempo; em seguida, a enzima oxida os ácidos clorogênicos, transformando-os em quinonas e a polifenoloxidase é inibida pelas quinonas formadas, diminuindo a sua atividade. Ataque de insetos, infecções microbianas, alterações fisiológicas e danos mecânicos pré e pós-colheita, provocam o rompimento da membrana celular, propiciando maior contato entre as enzimas e os compostos químicos que atuam dentro e fora das células do grão; as reações químicas resultantes modificam a composição original do café verde. O aumento da quantidade de fenóis oxidados, enzimaticamente ou não, provoca a inativação desta enzima.

Amorim \& Silva (1978) observaram, em seus estudos, maior atividade da polifenoloxidase nos cafés de melhor bebida. Os cafés de pior bebida tiveram em seu processamento condições favoráveis para que os polifenóis entrassem em contato com a polifenoloxidase, transformando-os em quinonas, alterando a coloração do grão e reduzindo a atividade da polifenoloxidase.

Tendo em vista as poucas informações sobre o efeito do tempo de armazenamento na deterioração do café preparado via seca e via úmida e visando estudar métodos simples, objetivos e mensuráveis para a avaliação da qualidade do café, este trabalho teve por objetivos:

- avaliar o efeito do tempo de armazenamento na qualidade do café "coco", "descascado" e beneficiado;

- avaliar a atividade da enzima polifenoloxidase (PPO) medida em espectrofotômetro, como método objetivo para a determinação da qualidade do café, comparando-o com o método sensorial clássico.

\section{MATERIAL E MÉTODOS}

O presente trabalho foi realizado nos Laboratórios dos Departamentos de Engenharia Agrícola, Bioquímica e Biologia Molecular, Engenharia Florestal e Fitotecnia da Universidade Federal de Viçosa, em Viçosa, MG, no período de 30 de março de 1997 a 30 de janeiro de 1998.

\section{Condicionamento dos grãos de café}

Durante o período de 10 meses foram armazenados três lotes de sacas de café (Coffea arabica L.) cada um, da variedade catuaí, provenientes do município de Viçosa, MG, o primeiro lote de café em coco, o segundo de café beneficiado, ambos pré-processados "via seca" e um terceiro lote de café descascado, pré-processado por "via úmida".

O lote de café beneficiado foi dividido em duas partes iguais para a coleta de amostras, por pertencer a dois produtores diferentes, porém o café pertencente ao produtor 1 foi colhido pelo processo de derriça no chão ("café de varrição") e o pertencente ao produtor 2 foi colhido pelo processo de derriça no pano. Os lotes de café coco e descascado também foram colhidos por derriça no pano.

Os três lotes foram então armazenados em sacos de aniagem, ou seja, de $60 \mathrm{~kg}$ de café beneficiado, $40 \mathrm{~kg}$ de café descascado e de $30 \mathrm{~kg}$ de café coco. Este material foi colocado sobre estrados, em armazém dotado de todas as condições necessárias ao armazenamento seguro do café. Cada lote teve lastros de cinco sacas e altura de pilha com quatro sacas.

A umidade relativa e a temperatura ambiente foram registradas por termohigrógrafo colocado no local.

\section{Amostragem experimental}

O experimento teve a duração de dez meses.

No decorrer deste período, foram feitas as coletas de amostra de dois em dois meses e, em seguida, a classificação do produto e os testes de qualidade de bebida, por métodos subjetivos e objetivos.

Um calador foi utilizado para se proceder à amostragem experimental. Todos os sacos de cada lote foram perfurados nas quatro faces de exposição no armazém. Após a coleta de todos os sacos, esta era misturada de forma que ficassem homogêneas e representativas para cada lote.

Em cada bateria de testes foi extraída uma amostragem geral de $2 \mathrm{~kg}$ de café coco, $1,5 \mathrm{~kg}$ de café descascado, $1 \mathrm{~kg}$ de café beneficiado do produtor $1 \mathrm{e} 1 \mathrm{~kg}$ de café beneficiado do produtor 2 .

\section{Avaliação sensorial}

Parte da amostragem geral ( $1 \mathrm{~kg}$ de café coco, $1 \mathrm{~kg}$ de café descascado, $0,5 \mathrm{~kg}$ de café beneficiado do produtor 1 e $0,5 \mathrm{~kg}$ de café beneficiado do produtor 2) foi enviada para a cooperativa dos produtores de café de Guaxupé, MG, onde foram realizados os testes de classificação quanto ao tipo e à cor. 


\section{Método químico}

Para determinação da atividade da polifenoloxidase (PPO) foi utilizada a metodologia descrita por Fujita et al. (1995) e realizadas as leituras de absorvância a $320 \mathrm{~nm}$, em espectrofotômetro. Utilizou-se o extrato da amostra sem floroglucinol a $20 \mathrm{~nm}$ como branco.

\section{Avaliação estatística}

Foram ajustadas equações de regressão para se estudar o efeito do tempo de armazenamento sobre as características em estudo.

\section{RESULTADOS E DISCUSSÃO}

\section{Análise sensorial}

Os resultados obtidos pela análise durante nos dez meses de armazenamento, encontram-se na Tabela 1, na qual se observa, que nos quatro tipos de café variou a coloração, porém os cafés Coco e Descascado variaram de verde-escuro para esverdeadoclaro e os cafés beneficiados do produtor 1 e do produtor 2 variaram de verde-escuro para branco. Esses resultados estão de acordo com a literatura que afirma que, durante o armazenamento convencional (estocagem em sacas de aniagem) os grãos perdem a cor com o tempo, fenômeno conhecido como "branqueamento". De acordo com Bacchi (1962) o branqueamento tem início em diferentes partes do grão, onde se alastra por toda a sua superfície.

Quanto à bebida observou-se, nos resultados obtidos pela análise sensorial, mudança da bebida no café descascado e alternância de bebidas no café beneficiado do produtor 1. Os cafés coco e beneficiado do produtor 2 mantiveram a mesma bebida durante os dez meses de armazenamento do produto (Tabela 1).

$\mathrm{O}$ café beneficiado do produtor 1 foi o de pior bebida inicial e final, em virtude da colheita ter sido feita por derriça no chão; este resultado está de acordo com Krug (1940) e Vilela (1997) que mostram, em seus estudos, que a derriça no chão propicia condições favoráveis ao desenvolvimento microbiológico e, consequentemente, fermentações indesejáveis, com formação de sabor estranho, alterando posteriormente a bebida.

A alternância entre duas bebidas, uma de qualidade superior e outra inferior (Riada e Rio) observada no café beneficiado do produtor 1 , é questionada devido à subjetividade do teste de análise sensorial. Esse fato está de acordo com Menchú (1967) e Carvalho (1994) que sugerem o complemento de métodos objetivos (físico-químicos e/ou químicos) juntamente com as classificações tradicionais proporcionando, assim, uma avaliação mais segura da qualidade deste produto.

\section{Método químico}

Os quatro tipos de café provenientes do experimento, depois da análise sensorial, foram submetidos às análises espectrofotométricas; essas análises constituíram-se na leitura de absorvância para determinar a atividade enzimática da polifenoloxidase (PPO).

Foram feitas análises de regressão para atividade da enzima polifenoloxidase nos quatro tipos de café em função do tempo de armazenamento.

Durante os dez meses de armazenamento foi constatada queda nas leituras de absorvância para atividade da PPO, nos quatro tipos de café (Tabela 2).

Tabela 2. Avaliação da atividade da polifenoloxidase (PPO) em amostras de café cru em pó, durante 10 meses de armazenamento

\begin{tabular}{|c|c|c|c|c|}
\hline \multicolumn{5}{|c|}{ Absorvância a $320 \mathrm{~nm}$} \\
\hline Tempo & Café & Café & Café & Café \\
\hline (dia) & Coco & Descascado & Beneficiado 1 & Beneficiado 2 \\
\hline 0 & 608 & 630 & 414 & 605 \\
\hline 60 & 594 & 623 & 403 & 593 \\
\hline 120 & 580 & 612 & 389 & 575 \\
\hline 180 & 576 & 605 & 378 & 561 \\
\hline 240 & 565 & 598 & 364 & 546 \\
\hline 300 & 565 & 594 & 371 & 554 \\
\hline
\end{tabular}

Tabela 1. Resultados obtidos pela análise sensorial dos diferentes tipos de café no experimento durante dez meses de armazenamento

\begin{tabular}{|c|c|c|c|c|c|c|}
\hline \multicolumn{7}{|l|}{ Café Coco } \\
\hline Bebida & Dura & Dura & Dura & Dura & Dura & Dura \\
\hline Cor & Verde escuro & Verde irregular & Amarelado & Verde claro & Esverdeado & Esverdeado \\
\hline Bebida & Apenas mole & Apenas mole & Apenas mole & Dura & Dura & Dura \\
\hline Cor & Verde escuro & Verde irregular & Amarelado & Esverdeado & Esverdeado & Esverdeado \\
\hline \multicolumn{7}{|l|}{ Café Beneficiado do Produtor 1} \\
\hline Bebida & Riada & Rio & Rio & Riada & Rio & Rio \\
\hline Cor & Verde escuro & Verde irregular & Manchado & Manchado & Manchado & Branco \\
\hline
\end{tabular}


Na Figura 1 observam-se as leituras de absorvância a 320nm para atividade da enzima polifenoloxidase, em função do tempo de armazenamento.

O café descascado, que na análise sensorial apresentou-se como de qualidade superior (apenas mole) entre os cafés existentes, apresentou também a maior atividade da PPO durante todo o período analisado, enquanto o café beneficiado do produtor 1 , que na análise sensorial mostrou ser o de pior qualidade de bebida (Riada) apresentou a menor atividade da PPO.

A Tabela 3 mostra as equações de regressão ajustadas e os coeficientes de determinação para a atividade da enzima polifenoloxidase $(\hat{Y})$ nos quatro tipos de café, em função do tempo de armazenamento (T).

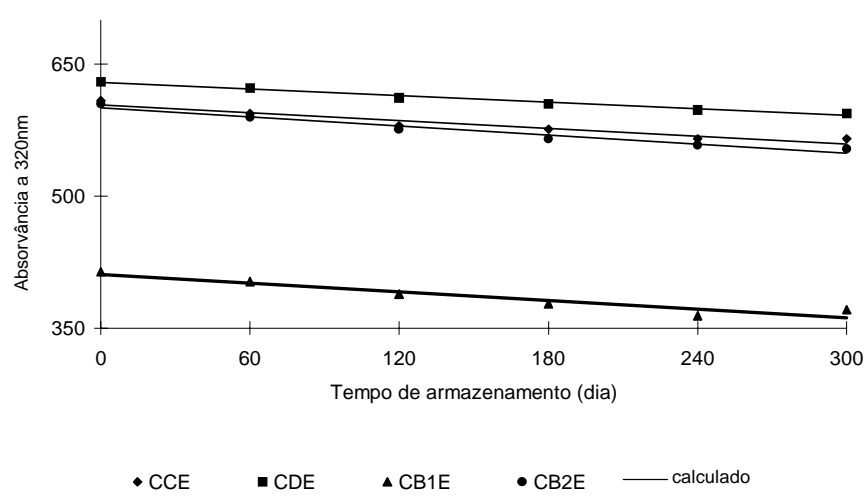

Figura 1 - Estimativas da atividade da enzima polifenoloxidase medida pela absorvância a 320nm nos cafés coco (CCE), descascado (CDE), beneficiado do produtor 1 (CB1E) beneficiado do produtor 2 (CB2E), em função do tempo de armazenamento $(\mathrm{T})$.

Tabela 3. Equações de regressão ajustadas para atividade da enzima polifenoloxidase $(\hat{Y})$ nos cafés coco (CCE), descascado (CDE), beneficiado do produtor 1 (CB1E) e beneficiado do produtor 2 (CB2E) em função do tempo de armazenamento (T) e os respectivos coeficientes de determinação

\begin{tabular}{ccc}
\hline $\begin{array}{c}\text { Tipo de } \\
\text { café }\end{array}$ & \multicolumn{1}{c}{ Equações de regressão } & $\mathrm{R}^{2}$ ajustado \\
\hline $\mathrm{CCE}$ & $\hat{\mathrm{Y}}=608,071-0,267738^{* *} \cdot \mathrm{T}+0,00040674^{*} \cdot \mathrm{T}^{2}$ & 0,99 \\
$\mathrm{CDE}$ & $\hat{\mathrm{Y}}=630,893-0,670893^{* *} \cdot \mathrm{T}+0,0005377^{*} \cdot \mathrm{T}^{2}$ & 0,99 \\
$\mathrm{CB} 1 \mathrm{E}$ & $\hat{\mathrm{Y}}=411-0,163^{* *} \cdot \mathrm{T}$ & 0,91 \\
$\mathrm{CB} 2 \mathrm{E}$ & $\hat{\mathrm{Y}}=601,619-0,195238^{* *} \cdot \mathrm{T}$ & 0,91 \\
\hline * - Significante a 5\% de probabilidade, pelo teste t & \\
** - Significante a 1\% de probabilidade, pelo teste t
\end{tabular}

Estes resultados mostraram que cafés de bebida de qualidade superior, apresentado na análise sensorial, tiveram maior atividade da enzima polifenoloxidase (PPO) podem ser explicados pelo preparo do café descascado, do qual são retiradas a casca e a mucilagem, fontes de fermentação prejudiciais à qualidade do café.

Esses resultados estão de acordo com Amorim \& Silva (1968) que observaram, em seus estudos, maior atividade da polifenoloxidase nos cafés de melhor bebida. Os cafés de pior bebida tiveram, em seu processamento, condições favoráveis para que os polifenóis entrassem em contato com a polifenoloxidase, proporcionando reações químicas que resultaram em decréscimo da atividade desta enzima.

A colheita inadequada (derriça no chão) foi prejudicial para o café beneficiado do produtor 1, tornando a bebida de qualidade inferior.

De acordo com Vilela (1997) a deterioração do produto é função da temperatura, da umidade relativa do ar e do tempo que o produto fica exposto na lavoura, após a derriça. A alta concentração de açúcares, juntamente com o teor de umidade elevada da polpa e mucilagem (70 a $90 \%$ b.u.), é condição excelente para o desenvolvimento microbiológico e, consequentemente, fermentações indesejáveis, com formação de sabor estranho alterando, posteriormente, a bebida.

\section{CONCLUSÕES}

Com base nos resultados obtidos nos testes experimentais, concluiu-se que:

1. A qualidade da bebida avaliada pelo "teste de xícara", manteve-se constante durante o armazenamento, exceto no caso do café descascado que, a partir de 6 meses, apresentou queda de qualidade.

2. Existe uma relação direta entre a PPO e a qualidade da bebida.

3. Durante o período de armazenamento todos os tipos de cafés apresentaram variação de cor, tendendo ao branqueamento; no café beneficiado, esta tendência foi mais marcante.

\section{REFERÊNCIAS BIBLIOGRÁFICAS}

AMORIM, H.V. Aspectos bioquímicos e histoquímicos do grão de café verde relacionados com a deterioração da qualidade. Piracicaba: ESALQ, 1978. 85p. (Tese de Livre Docência em Bioquímica)

AMORIM, H.V.; SILVA, D.M. Relação da atividade da polifenoloxidase do grão de café (Coffe arabica $\mathrm{L}$.) com a qualidade da bebida. Piracicaba: ESALQ, 1968. 16p. (Boletim Técnico, 31)

BACCHI, O. O branqueamento dos grãos de café. Bragantia, Campinas, v.21, n.28, p.476-84, 1962.

CARVALHO, V.D.; CHAGAS, S.J.R.; CHALFOUN, S.M.; BOTREL, N.; JUSTE Jr., E.S.G. Relação entre a composição físico-química e química do grão de café beneficiado e a qualidade de bebida do café. Pesquisa Agropecuária Brasileira, Brasília, v.29, n.3, p.449-454, 1994.

FUJITA, S.; SAARI, N.; MAEGAWA, M.; TESTUKE, T:, HAYASHI, N:, TONO, T:, Purification and properties of polyphenol oxidase from cabbage (Brassica oleracea L.). Journal Agricultural Food Chemistry, v. 43, p.113842,1995.

KRUG, H.P. Cafés duros: II - um estudo sobre a qualidade dos cafés de varrição. Revista do Instituto do Café, São Paulo, v.27, n.163, p.1393-1396, set. 1940.

MENCHÚ, E.F. La determinación de la calidad del café. Parte 1. Características, color y aspecto. Agricultura de las Americas, Kansas City, Missouri, 16(5):18-21, mayo 1967. VILELA, E.R. Secagem e qualidade do café. Informe Agropecuário, Belo Horizonte, v.1: n.187, p.63-67, Jun., 1997. 